\title{
Operational Methods for Charging of Electric Vehicles
}

\author{
Bálint Csonka1*, Márton Havas¹, Csaba Csiszár, Dávid Földes \\ ${ }^{1}$ Department of Transport Technology and Economics, Faculty of Transportation Engineering and Vehicle Engineering, Budapest \\ University of Technology and Economics, H-1111 Budapest, Múegyetem rkp. 3., Hungary \\ * Corresponding author, e-mail: csonka.balint@mail.bme.hu
}

Received: 03 March 2020, Accepted: 11 March 2020, Published online: 29 July 2020

\begin{abstract}
The increasing number of electric vehicles induces a new relationship between the electric vehicles, transportation network and electric network. The deployment of the charging infrastructure is a prerequisite of the widespread of electric vehicles. Furthermore, the charging process and energy management have a significant influence on the operation of both the transportation and electric networks. Therefore, we have elaborated novel operational methods that support the deployment of charging infrastructure for electric cars and buses operating in public bus service, and the energy management. Weighted sum-models were developed to assess candidate sites for public charging stations. The mathematical model of public bus services was elaborated that supports the optimization of static charging infrastructure at bus stops and terminals without schedule adjustments. The flexibility and predictability of charging sessions were identified as the main differences between charging infrastructure deployment for cars and buses. Furthermore, the flows of energy, information and value have been revealed among the components of charging with a focus on commercial locations, which is the basis of energy flow optimization on the smart grid.
\end{abstract}

\section{Keywords}

electric car, electric bus, charging infrastructure, energy management

\section{Introduction}

In line with EU objectives, the number of Battery Electric Vehicles (BEV) is increasing in Europe. Besides the positive characteristic of BEVs, such as zero local emission, the long charging time and limited range are identified as significant drawbacks in comparison with the conventional vehicles. Furthermore, the spread of BEVs is slowed down by the, incomplete charging infrastructure, scant experience on BEV use, and regulatory hurdles (Vokony et al., 2020). The effect of vast charging demand on the electricity network is also uncertain. In other words, electromobility is a complex system with several actors, components and processes. Usually, the vehicle is put in the focus of researchers. Albeit, the key to success is a cooperation between legislation, vehicle industry, electric industry, transportation management centers, operators and travelers.

In the case of electric cars, the main problem is that the charging process decreases the flexibility of car use because of the long charging time and limited range. Hence, the aim is to seamlessly fit the charging process to the car users' travel behavior. The return of charging station installation is not guaranteed in the absence of mass market. Hence, the location and the utilization are critical in the mean of deploying charging stations in the early phase of electromobility. Therefore, charging station locating methods were elaborated.

The electric drivetrain is especially favorable in vehicles with high annual mileage, such as city buses operating in public transportation. Furthermore, the $\mathrm{CO}_{2}$ emission reduction affects a vast majority of people in dense areas. Accordingly, the number of launched electric buses is more than 2500 in 19 cities until the end of 2020 (UITP, 2016). In contrast to the car, the movements of public buses are non-flexible. The aim is to reveal the periods when the vehicles can be charged with a minimum adverse effect on the utilization. Therefore, the aim is to elaborate the mathematical model of the bus service and a method for infrastructure deployment. The cars should be charged during parking and buses should be charged along the service routes. Therefore, different approaches are needed to determine the appropriate charging infrastructure for cars and buses.

In accordance with EU directives and Hungarian legislation, charging stations for BEVs should be provided on the base of parking places in offices and commercial buildings (Lopez-Behar et al., 2019). The lack of proper 
power network to cover the charging demand of BEVs is a common barrier to charging station installation. Charging management is an efficient tool to manage limited capacities. Therefore, the aim was to reveal the components and the processes such as flows of energy, information and value, which are the base of charging management.

The structure of the paper is the following: after a brief literature review in Section 2, we present our latest results succinctly in the field of operational methods for charging of electric vehicles. The public charging station deployment method for long journeys and urban areas are presented in Section 3. The model of public bus service is summarized in Section 4. The optimization of electric vehicle charging in offices and commercial buildings are presented in Section 5. Finally, the conclusion has been drawn.

\section{Literature review}

According to the differences, two types of charging demands had been distinguished in the literature:

- during long-journeys (inter-city) and

- at the end of short trips (intra-city).

In the first case, the journey is interrupted by the charging process. It causes a time loss which should be minimized. In the latter case, the usefulness of parking sessions is extended by the charging process. Different approaches in charging station deployment are required by the different demands.

In papers dealing with charging demand on a regional scale, flow-based (Hodgson, 1990) or Flow Capturing Location-Allocation Models (FCLM) are highly usable. A particle swarm optimization model based on FCLM is presented in Lin and Hua (2015). The selection of charging stations is performed according to the installation cost, the service area of a charging station and the volume of traffic flow. The FCLM model was extended with a refueling-logic by Kuby and Lim (2005). According to the Flow Refueling Location Model (FRLM), a flow is captured if it never runs out of energy. Further extensions were also made, such as the interpretation of candidate sites (Davidov and Pantoš, 2017; Kuby and Lim, 2007) and introduction of threshold coverage to set a preference on served roundtrips (Hong and Kuby, 2016). FRLMs require data about origin and destination (O-D) flows which are not always available. Therefore, arc-based approaches emerged that provide good coverage of flows in the absence of O-D data (e.g. Boostani et al., 2010; Zhong et al., 2019).
Node-based or point-demand models (Melkote and Daskin, 2001) are more preferred in papers focusing on intra-city charging demand because the demand is concentrated. Since the average total parking time of a vehicle is more than 20 hours, the vehicle may be charged during parking. Hence, several intra-city charging station location methods are based on the parking behavior (e.g. Andrenacci et al., 2016; De Gennaro et al., 2015). However, there are different approaches too. Both Cai et al. (2014) and Shahraki et al. (2015) analyzed the routes of cabs to identify the busiest nodes. Xydas et al. (2016) derived the charging station locations from current electric vehicles use. It was found that charging stations at shopping centers are the most popular among the public stations. Albeit, the low number of electric vehicles may have a significant effect on the result.

The number of papers dealing with the deployment of charging infrastructure for electric buses increased significantly in recent years. Most of the researches focus on the technology, environmental aspects, energy management and cost analysis (e.g. Du et al., 2018; Jwa and Lim, 2018; Laib et al., 2019; Ye et al., 2019). The charging infrastructure deployment methods usually consider either wired or wireless, and static or in-movement charging technologies. Kunith et al. (2017) considered shared bus stops as candidate sites for wireless chargers and revealed a trade-off between battery capacity and charging infrastructure. Bi et al. (2018) considered wireless charging technologies and found that charging infrastructure planning based on the characteristic of the bus network may decrease the cost of electrification significantly. Close to our aims, Xylia et al. (2017) considered both the wired and wireless technologies to determine the most favorable bus lines in the mean of the electrification cost. The combined use of different technologies was not analyzed.

Extensive research is available in the field of energy optimization of buildings considering BEVs. These kinds of vehicles can be used for smart grid applications such as vehicle-to-grid (V2G), grid-to-vehicle (G2V), peak-shaving and load-shifting (Amirioun and Kazemi, 2014; Genikomsakis et al., 2016; Ioakimidis et al., 2018; Tsai-Hsiang and Rih-Neng, 2013). Nevertheless, little research has addressed how the capacities of a building should be allocated according to the mobility needs of BEV users. A comprehensive study has been carried out to analyze how these mobility needs can be matched to the building's available energy and charging capacities. 


\section{Public charging station deployment}

Two charging station deployment methods were elaborated because of the differences between inter-city and intra-city charging demand. The goal was to fit the locations to the driving behavior of private car users. However, public car users, such as taxi drivers and carsharing customers, should also use the charging infrastructure, but their preferences on the charging station location were not revealed in this study.

\subsection{Inter-city charging station locating method}

An arc-based inter-city charging station deployment method was elaborated. The rest-areas were identified as candidate sites for charging station installation. The deployment of rapid chargers was proposed to minimize the time loss. The Installation Potential (IP) of each candidate site was evaluated. IP is a function of traffic volume, population of nearby settlements, available services and the distance to the nearest fast-charging station. The traffic volume of the nearest arc was considered. Thus, EV users who may take a detour to recharge are neglected. However, there are other methods where each arc in a specific service area is considered (e.g. Zhong et al., 2019). In contrast to these approaches, the population of nearby settlements was considered to catch the effect of latent demand on utilization. The services at rest-areas are evaluated to provide valuable means of charging time, which is the main novelty of the method. The effect of existing fast-charging stations was interpreted by two geographical parameters that determined the favorable distance from an existing station of an additional installation site. Thus, the covered area spreads like an oil-stain, and even spatial distribution may be achieved.

Various road categories may be considered on several layers. Thus, high-capacity road categories may be prioritized. Albeit, the effect of the toll on route selection is not assessed, toll roads may be considered on different layers.

The selection of proposed installation sites was performed separated using the greedy algorithm. Namely, the objective function was to maximize the total IP of proposed installation sites. Before each selection, the candidate sites are re-evaluated. Additional candidate sites are selected until a termination criterion is fulfilled. The termination criterion may be the number of charging stations to be deployed or the minimum increment of covered road length when adding a new location.

The method was applied for Hungary and was validated using O-D data about long-journeys. It was found that in lack of O-D data about traffic flows, the developed arc-based method provides a high share of served traffic volume.

\subsection{Intra-city charging station locating method}

The intra-city charging demand was evaluated on macro and meso levels which is the main novelty of the method. On the macro level, areas, such as counties, were compared based on the possibility of EV use. EV use was estimated as a function of the number of registered EVs, average income and the importance of tourism. The aim at the macro level is to distribute the charging stations to be deployed among the areas. The modification of model parameters may contribute to a more balanced distribution.

On the meso level, the areas are divided into hexagons. The distance between two parallel sides of a hexagon is $250 \mathrm{~m}$. Hexagonal tessellation was used because it reduces sampling bias because of the low perimeter-to-area ratio. Furthermore, the neighboring hexagons may be identified easily. The hexagons are compared on the base of charging demand to determine the favorable locations for charging stations. The charging demand in a hexagon was determined as the weighted sum of daytime and nighttime charging demand. Daytime charging demand is a function of the average parking time and frequency at available services. The parking time and frequency were determined using a survey. Current and potential EV users participated in the survey. Nighttime charging demand is a function of population and residential area type. The willingness to walk was also considered, which is the highest distance that a car user would walk between the parking space and its destination. Thus, a charging station located in a hexagon may serve the charging demand of the neighboring hexagons as well. The deployment of fast chargers is proposed at location types where the share of daytime charging demand is significant (e.g. at supermarkets, sport and recreational facilities). Consequently, the deployment of slow chargers is proposed at location types where the share of nighttime charging demand is significant (e.g. at residential parking facilities).

The method was applied for Hungary on the macro level, and district 11 in Budapest on meso level. It was found that the method supports the distribution and location of charging stations efficiently. Furthermore, deployment of fast-charging stations is not advised to serve the intra-city charging demand because of the available long (> $30 \mathrm{~min}$ ) parking times. 


\section{Charging infrastructure deployment to serve public bus service}

The model of public bus service was elaborated, which is the base of charging infrastructure optimization. The aim was to define the electrification cost as a function of charged energy at candidate sites. The deployment of a charging unit is proposed at a candidate site if the volume of charged energy is not zero after the optimization.

\subsection{Physical model}

The round trips of bus lines were analyzed. Therefore, the following assumptions were made about the bus service:

- A homogeneous bus fleet serves each bus line. However, the characteristic of buses operating on various lines may differ.

- Buses may be charged at both wired and wireless chargers.

The following components of the bus network were considered:

- terminal: the dwelling time is significant. It is candidate site for wired charging units.

- bus stop: the dwelling time is short. It is candidate site for wireless charging units.

The components and energy flows of the physical model are given in Fig. 1.

The energy consumption generated by the movement of the bus was considered. On-board energy consumers, such as heater and air conditioner, were neglected. The following limitations were applied to the charging units:

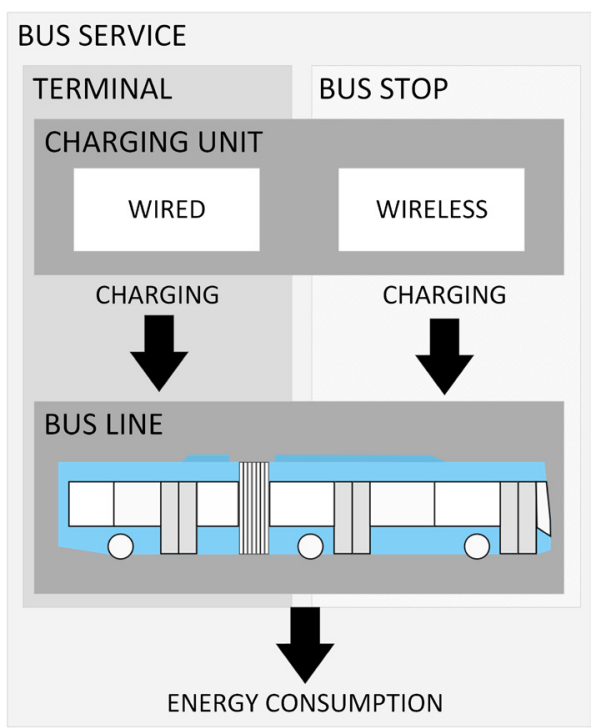

Fig. 1 The components and energy flows in the physical model
- The cost of a charging unit may contain the installation and operational costs. It depends on the objective of the application.

- The total cost of charging units at a candidate site is the charging unit cost multiplied by the number of proposed chargers. In other words, the cost of electricity network development was neglected.

\subsection{Mathematical model}

The mathematical model defines the relationships among the components of the physical model (input) and the cost of electrification (output). The parameters of the mathematical model are summarized in Table 1.

The maximum utility of charging units may differ. For example, the utility of wired chargers is lower in comparison to the wireless chargers because of the connection and disconnection times. The charging infrastructure is determined on the base of the highest energy demand, which occurs during the peak hour. Therefore, the number of round trips during peak hour was considered. The parameters are either one- or two-dimensional. The one-dimensional parameters are either location (bus stop and terminal) or bus line specific. These are row and column vectors, respectively. Two-dimensional parameters are both location and bus line specific. These parameters are matrices.

The location-specific parameters are as follows Eq. (1) to Eq. (3):

$$
\begin{aligned}
& \boldsymbol{C}^{\boldsymbol{u}}=\left[\begin{array}{lll}
c_{1}^{u} & c_{j}^{u} & c_{n}^{u}
\end{array}\right], \\
& \boldsymbol{P}=\left[\begin{array}{lll}
p_{1} & p_{j} & p_{n}
\end{array}\right], \\
& \boldsymbol{M}=\left[\begin{array}{lll}
\mu_{1} & \mu_{j} & \mu_{n}
\end{array}\right],
\end{aligned}
$$

\begin{tabular}{|c|c|c|}
\hline Component & Symbol & Description \\
\hline \multirow[b]{3}{*}{ Charging unit } & $c^{u}$ & Cost of a charging unit $[€]$ \\
\hline & $p$ & Charging power $[\mathrm{kW}]$ \\
\hline & $\mu$ & $\begin{array}{l}\text { Maximum utility of a charging unit } \\
\text { according to the specialties, between } 0 \\
\text { and } 1 \text { [hour] }\end{array}$ \\
\hline $\begin{array}{l}\text { Energy } \\
\text { consumption }\end{array}$ & $e^{-}$ & $\begin{array}{l}\text { Energy consumption of a round trip } \\
\qquad[\mathrm{kWh}]\end{array}$ \\
\hline \multirow{3}{*}{ Charging } & $e^{+}$ & $\begin{array}{l}\text { Maximum volume of charged energy } \\
\text { during a round trip [kWh] }\end{array}$ \\
\hline & $x$ & $\begin{array}{l}\text { Volume of charged energy during a round } \\
\text { trip }[\mathrm{kWh}]\end{array}$ \\
\hline & $d$ & Energy demand in peak hour [kWh] \\
\hline Bus line & $f$ & $\begin{array}{l}\text { Number of round trips at a bus line in } \\
\text { peak hour [-] }\end{array}$ \\
\hline
\end{tabular}

Table 1 Parameters of public bus service model 
where:

$C^{u} \quad$ charging unit cost row vector.

$c_{j}^{u} \quad$ charging unit cost at bus stop or terminal $j$.

$P \quad$ charging power row vector.

$p_{j} \quad$ charging power at bus stop or terminal $j$.

$\boldsymbol{M}$ maximum utility row vector.

$\mu_{j} \quad$ maximum utility at bus stop or terminal $j$.

$n \quad$ total number of bus stops and terminals.

The bus line specific energy consumption and the number of round trips are given in Eqs. (4) and (5).

$$
\begin{gathered}
\boldsymbol{E}^{-}=\left[\begin{array}{l}
e_{1}^{-} \\
e_{i}^{-} \\
e_{k}^{-}
\end{array}\right], \\
\boldsymbol{F}=\left[\begin{array}{l}
f_{1} \\
f_{i} \\
f_{k}
\end{array}\right],
\end{gathered}
$$

where:

$\boldsymbol{E}^{-} \quad$ energy consumption column vector.

$e_{i}^{-} \quad$ energy consumption of bus line $i$.

$\boldsymbol{F}$ number of round trips column vector.

$f_{i} \quad$ number of round trips on bus line $i$.

$k \quad$ total number of bus lines.

The maximum volume of charged energy is given in Eq. (6):

$$
\boldsymbol{E}^{+}=\left[\begin{array}{ccc}
e_{1,1}^{+} & & e_{1, n}^{+} \\
& e_{i, j}^{+} & \\
e_{k, 1}^{+} & & e_{k, n}^{+}
\end{array}\right],
$$

where:

$\boldsymbol{E}^{+} \quad$ maximum volume charged energy matrix.

$e_{i, j}^{+} \quad$ maximum volume of charged energy on bus line $i$ at bus stop or terminal $j$.

The prerequisite of electrification is given in Eq. (7). Namely, the electrification is possible if the maximum volume of charged energy is higher than the energy demand. $e_{i}^{-} \leq \sum_{j} e_{i, j}^{+}$

The volume of charged energy during a round trip is given in Eq. (8):

$\boldsymbol{X}=\left[\begin{array}{ccc}x_{1,1} & & x_{1, n} \\ & x_{i, j} & \\ x_{k, 1} & & x_{k, n}\end{array}\right]$,

where:

$\boldsymbol{X} \quad$ volume charged energy matrix.

$x_{i, j} \quad$ volume of charged energy on bus line $i$ at bus stop or terminal $j$.
The energy demand is calculated according to Eq. (9).

$\boldsymbol{F} \times \boldsymbol{X}=\boldsymbol{D}=\left[\begin{array}{lll}d_{1,1} & & d_{1, n} \\ & d_{i, j} & \\ d_{k, 1} & & d_{k, n}\end{array}\right]$,

where:

D energy demand matrix.

$d_{i, j} \quad$ energy demand of bus line $i$ at bus stop or terminal $j$.

The total energy demand at a bus stop or terminal is calculated according to Eq. (10):

$d_{j}=\sum_{j} d_{i, j}$.

\subsection{Constraints}

The solution of the optimization is valid if the following constraints are satisfied:

- Equation (11): the volume of charged energy is between zero and the maximum volume of charged energy.

- Equation (12): the total energy demand at a bus stop and terminal is lower than or equals to the charging capacity. The multiplication of charging power and maximum utility is the charging capacity.

- Equation (13): the total charged energy is higher than or equals to the energy consumption for each bus line.

$$
\begin{aligned}
& 0 \leq x_{i, j} \leq e_{i, j}^{+} \forall i=1 . . k \text { and } \forall j=1 . . n \\
& d_{j} \leq p_{j} \cdot \mu_{j} \forall j=1 . . n \\
& \sum_{j} x_{i, j} \geq e_{i}^{-} \forall i=1 . . k
\end{aligned}
$$

\subsection{Objective function}

The objective of the optimization is to serve the energy demand at minimum cost. The cost of electrification is not a continuous function of charging demand because it increases step by step when an additional charging unit is added to the infrastructure. Hence, the substitute cost function $\left(c^{s}\right)$ was interpreted in Eq. (14):

$c_{j}^{s}=\left(\frac{-1}{50\left(d_{j}-\left\lfloor\frac{d_{j}}{p_{j} \mu_{j}}\right\rfloor \cdot p_{j} \mu_{j}\right)+1}+1\right) \cdot c_{j}$

$+\left\lfloor\frac{d_{j}}{p_{j} \mu_{j}}\right\rfloor \cdot\left(\frac{-1}{50 p_{j} \mu_{j}+1}+1\right) \cdot c_{j}$, 
where:

$c_{j} \quad$ substitute cost function of charging infrastructure at bus stop or terminal $j$.

The difference between the real and substitute cost functions is presented in Fig. 2.

The objective function is given by Eq. (15). Namely, the aim is to minimize the total substitute cost.

$$
\operatorname{MIN}\left(\sum_{j} c_{j}^{s}(X)\right)
$$

However, the charged energy is the variable, and the cost minimalization is the objective; the public bus service model may be applied to determine the following parameters of the charging infrastructure:

- location,

- charging power,

- number of chargers.

Furthermore, the effects of scheduling on charging infrastructure cost may be analyzed through parameter $f$.

\section{Energy management of buildings to serve charging demand}

Buildings and BEVs are part of a complex transport, energy and information system that needs to be examined before analyzing potential optimization opportunities. In many cases, the building is not interacting with the BEV itself, and there are also other system elements like the electricity grid, the rooftop solar photovoltaic system, the Building Management System, the Charge Management System and also the Charger. Energy, information and value flows have been identified among them.

We investigated in this research, how these interactions change when we add the mobility demand layer. Two types of BEV user needs were considered:

- travel needs,

- charging needs.

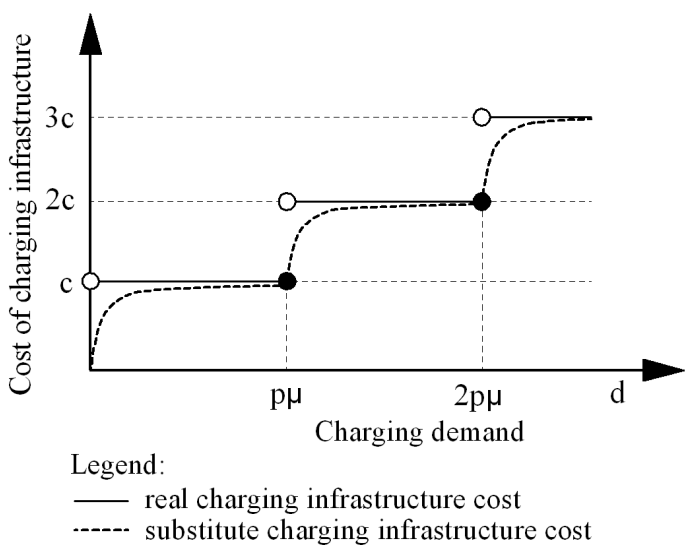

Fig. 2 Real and substitute charging infrastructure cost functions
When the building's ability to take power from the grid is limited (e.g. because of a transformer or most of the BEV charging points are occupied) an optimization is needed so that the system can work while minimizing costs and maximizing revenue.

The optimization of this system can be done through the following options:

- dynamic pricing of electricity,

- dynamic pricing of charging or

- dynamic pricing of charging and electricity.

This is because capacities and needs have significant variations over time. When a peak on the electricity grid occurs, the electricity provider should charge more for electricity, while the building should also charge more for BEV charging during the same period. Similarly, the BEV user who wants to charge at higher power should pay more than the user whose $\mathrm{BEV}$ requires only a lower power.

\section{Conclusion}

Charging infrastructure deployment methods have been presented for cars. The mathematical model of public bus service was elaborated, that is the base of infrastructure optimization. The model supports the combined use of wired and wireless static chargers. The main findings of the paper are the differences between charging demands; namely, their flexibility and predictability. The parking time of cars is high, but it is difficult to predict the exact location and time of parking. Similarly, the routes are also challenging to predict. Thus, the aim was to identify the most likely locations for charging.

On the contrary, the high utilization of public buses reduces the options significantly for charging. However, the solution of the optimization is more reliable because the movements of buses are well-known, and the energy demand may be predicted easily.

The increasing number of BEVs and the limited resources in the electricity network of commercial buildings require an optimized system that interacts with all elements to minimize costs and maximize revenue. This optimization can be executed through a dynamic pricing function, that balances the capacities of the building with the mobility and charging needs of BEVs.

Our next objective in the field of charging infrastructure deployment is to involve in-movement chargers into optimization of bus charging infrastructure. In the field of energy management, we are planning to model the energy flows among electric cars, rooftop solar panels and the electric grid in offices and commercial buildings. 


\section{Acknowledgement}

The research reported in this paper was supported by the Higher Education Excellence Program in the frame of Artificial Intelligence research area of Budapest University of Technology and Economics (BME FIKP-MI/FM).

\section{References}

Amirioun, M. H., Kazemi, A. (2014) "A new model based on optimal scheduling of combined energy exchange modes for aggregation of electric vehicles in a residential complex", Energy, 69, pp. 186-198. https://doi.org/10.1016/j.energy.2014.02.063

Andrenacci, N., Ragona, R., Valenti, G. (2016) "A demand-side approach to the optimal deployment of electric vehicle charging stations in metropolitan areas", Applied Energy, 182, pp. 39-46. https://doi.org/10.1016/j.apenergy.2016.07.137

Bi, Z., Keoleian, G. A., Ersal, T. (2018) "Wireless charger deployment for an electric bus network: A multi-objective life cycle optimization", Applied Energy, 225, pp. 1090-1101. https://doi.org/10.1016/j.apenergy.2018.05.070

Boostani, A., Ghods, R., Miab, A. K. (2010) "Optimal Location of Compressed Natural Gas (CNG) Refueling Station Using the Arc Demand Coverage Model", In: 2010 Fourth Asia International Conference On Mathematical/Analytical Modelling and Computer Simulation, Bornea, Malaysia, pp. 193-198. https://doi.org/10.1109/AMS.2010.49

Cai, H., Jia, X., Chiu, A. S. F., Hu, X., Xu, M. (2014) "Siting public electric vehicle charging stations in Beijing using big-data informed travel patterns of the taxi fleet", Transportation Research Part D: Transport and Environment, 33, pp. 39-46. https://doi.org/10.1016/j.trd.2014.09.003

Davidov, S., Pantoš, M. (2017) "Planning of electric vehicle infrastructure based on charging reliability and quality of service", Energy, 118, pp. 1156-1167. https://doi.org/10.1016/j.energy.2016.10.142

De Gennaro, M., Paffumi, E., Martini, G. (2015) "Customer-driven design of the recharge infrastructure and Vehicle-to-Grid in urban areas: A large-scale application for electric vehicles deployment", Energy, 82, pp. 294-311. https://doi.org/10.1016/j.energy.2015.01.039

Du, J., Zhang, X., Wang, T., Song, Z., Yang, X., Wang, H., Ouyang, M., Wu, X. (2018) "Battery degradation minimization oriented energy management strategy for plug-in hybrid electric bus with multi-energy storage system", Energy, 165, pp. 153-163. https://doi.org/10.1016/j.energy.2018.09.084

Genikomsakis, K. N., Bocquier, B., Lopez, S., Ioakimidis, C. S. (2016) "Utilizing plug-in electric vehicles for peak shaving and valley filling in non-residential buildings with solar photovoltaic systems", In: 2016 5th International Conference on Smart Cities and Green ICT Systems (SMARTGREENS), Rome, Italy, pp. 1-10.

Hodgson, M. J. (1990) "A Flow-Capturing Location-Allocation Model", Geographical Analysis, 22(3), pp. 270-279. https://doi.org/10.1111/j.1538-4632.1990.tb00210.x

Hong, S., Kuby, M. (2016) "A threshold covering flow-based location model to build a critical mass of alternative-fuel stations", Journal of Transport Geography, 56, pp. 128-137. https://doi.org/10.1016/j.jtrangeo.2016.08.019
EFOP-3.6.3-VEKOP-16-2017-00001: Talent management in autonomous vehicle control technologies - The Project is supported by the Hungarian Government and co-financed by the European Social Fund.

Ioakimidis, C. S., Thomas, D., Rycerski, P., Genikomsakis, K. N. (2018) "Peak shaving and valley filling of power consumption profile in non-residential buildings using an electric vehicle parking lot", Energy, 148, pp. 148-158.

https://doi.org/10.1016/j.energy.2018.01.128

Jwa, K., Lim, O. (2018) "Comparative life cycle assessment of lithium-ion battery electric bus and Diesel bus from well to wheel", Energy Procedia, 145, pp. 223-227.

https://doi.org/10.1016/j.egypro.2018.04.039

Kuby, M., Lim, S. (2005) "The flow-refueling location problem for alternative-fuel vehicles", Socio-Economic Planning Sciences, 39(2), pp. $125-145$.

https://doi.org/10.1016/j.seps.2004.03.001

Kuby, M., Lim, S. (2007) "Location of Alternative-Fuel Stations Using the Flow-Refueling Location Model and Dispersion of Candidate Sites on Arcs", Networks and Spatial Economics, 7(2), pp. 129-152. https://doi.org/10.1007/s11067-006-9003-6

Kunith, A., Mendelevitch, R., Goehlich, D. (2017) "Electrification of a city bus network-An optimization model for cost-effective placing of charging infrastructure and battery sizing of fast charging electric bus systems", International Journal of Sustainable Transportation, 11(10), pp. 707-720. https://doi.org/10.1080/15568318.2017.1310962

Laib, F., Braun, A., Rid, W. (2019) "Modelling noise reductions using electric buses in urban traffic. A case study from Stuttgart, Germany.", Transportation Research Procedia, 37, pp. 377-384. https://doi.org/10.1016/j.trpro.2018.12.206

Lin, W., Hua, G. (2015) "The flow capturing location model and algorithm of electric vehicle charging stations", In: 2015 International Conference on Logistics, Informatics and Service Sciences (LISS), Barcelona, Spain, pp. 1-6. https://doi.org/10.1109/LISS.2015.7369788

Lopez-Behar, D., Tran, M., Froese, T., Mayaud, J. R., Herrera, O. E., Merida, W. (2019) "Charging infrastructure for electric vehicles in Multi-Unit Residential Buildings: Mapping feedbacks and policy recommendations", Energy Policy, 126, pp. 444-451. https://doi.org/10.1016/j.enpol.2018.10.030

Melkote, S., Daskin, M. S. (2001) "Capacitated facility location/network design problems", European Journal of Operational Research, 129(3), pp. 481-495. https://doi.org/10.1016/S0377-2217(99)00464-6

Shahraki, N., Cai, H., Turkay, M., Xu, M. (2015) "Optimal locations of electric public charging stations using real world vehicle travel patterns", Transportation Research Part D: Transport and Environment, 41, pp. 165-176. https://doi.org/10.1016/j.trd.2015.09.011 
Tsai-Hsiang, C., Rih-Neng, L. (2013) "Analysis of Charging Demand of Electric Vehicles in Residential Area", In: 2013 the International Conference on Remote Sensing, Environment and Transportation Engineering (RSETE 2013), Nanjing, China, pp. 27-31.

https://doi.org/10.2991/rsete.2013.7

UITP (2016) "ZeEUS eBus Report: An overview of electric buses in Europe", [pdf], Available at: http://zeeus.eu/uploads/publications/documents/zeeus-ebus-report-internet.pdf [Accessed: 10 February 2020]

Vokony, I., Hartmann, B., Kiss, J., Sörés, P., Farkas, Cs. (2020) "Business Models to Exploit Possibilities of E-mobility: An Electricity Distribution System Operator Perspective", Periodica Polytechnica Transportation Engineering, 48(1), pp. 1-10. https://doi.org/10.3311/PPtr.13471

Xydas, E., Marmaras, C., Cipcigan, L. M., Jenkins, N., Carroll, S., Barker, M. (2016) "A data-driven approach for characterising the charging demand of electric vehicles: A UK case study", Applied Energy, 162, pp. 763-771.

https://doi.org/10.1016/j.apenergy.2015.10.151
Xylia, M., Leduc, S., Patrizio, P., Silveira, S., Kraxner, F. (2017) "Developing a dynamic optimization model for electric bus charging infrastructure", Transportation Research Procedia, 27, pp. 776-783.

https://doi.org/10.1016/j.trpro.2017.12.075

Ye, L., Liang, C., Liu, Y., Li, D., Liu, Z. (2019) "Performance analysis and test of a novel eddy-current braking \& heating system for electric bus", Energy Conversion and Management, 183, pp. 440-449. https://doi.org/10.1016/j.enconman.2019.01.010

Zhong, Q., Tong, D., Kuby, M., Wei, F., Fowler, J., Bailey, K. (2019) "Locating Alternative Fuel Stations for Maximizing Coverage and Ensuring Sufficient Spacing: a Case Study of CNG Truck Fueling", Process Integration and Optimization for Sustainability, 3(4), pp. 455-470.

https://doi.org/10.1007/s41660-019-00092-9 